\title{
PROPUESTA DE UN MODELO DE DESARROLLO PARA UNA COMUNIDAD RURAL MEXICANA, MARGINADA POR EL DIFÍCIL ACCESO Y POR LA FALTA DE SATISFACTORES BÁSICOS ${ }^{1}$
}

Ana Teresa López de Llergo Luz Ma. Cruz de Galindo

\section{RESUMEN}

ESTE ARTÍCULO PRESENTA UN MODELO DE DESARROLO COMO SUGERENcia para que lo adopten y adapten otras comunidades en condiciones semejantes.

Plantea que el desarrollo es posible cuando las comunidades realizan sus proyectos y respetan su identidad. Si el modelo es de gabinete resulta anacrónico o impositivo. Hay que partir de casos concretos, buscaraspectos generalizablesy haceradaptaciones en la comunidad. El promotorcomunitario ha de conocer las ciencias sociales y auxiliarse de una tecnología para establecer las vías de desamollo.

\section{ABSTRACT}

This article presents, as a suggestion, a model of development to be adopted and adapted by other communities in similarcircumstances.

It states that development comes when the communities carry out their projects and respect their identity. If the model is carried in an office, itbecomes an anachronism or an imposition. We have to startfrom specific cases, look for generalizing aspects and adapt them to the community. The communitarian promotermust know the social sciences and get help from a technology to establish the development paths. 


\section{LO GENÉRICO QUE HACE A LA COMUNIDAD SER LO QUE ES,Y LO ESPECÍFICO QUE LE DA UNA IDENTIDAD SINGULAR A CADA UNA}

Los aspectos comunitanios genéncos se identifican con la esencia de un grupo. Si falta alguno, deja de ser comunidad. Lo genérico responde a la pregunta quées Lo específico es el modo como se manifiesta esa comunidad, las características propias que le dan una identidad singular. Responde a la pregunta cómo es.

Por comunidad entendemos:

Una agrupación o conjunto de personas que habitan un espacio geográfico delimitado y delimitable, cuyos miembros tienen conciencia de pertenencia o de identificación con algún símbolo local y que interaccionan entre sí más intensamente que en otro contexto, operando en redes de comunicación, interesesy apoyo mutuo, con el propósito de alcanzar determinados objetivos, satisfacer necesidades, resolverproblemas o desempeñarfunciones sociales relevantes a nivel local ${ }^{2}$.

De acuerdo con esta definición encontramos las siguientes notas esenciales - genéricas- de una comunidad:

- Espacio geográfico determinado 3 .

- Personasagrupadas.

- Conciencia de pertenencia al grupo y al espacio geográfico.

- Identificación con símbolos, nitos y tradiciones.

- Interacción más intensa que en otros contextos, lo que favorece el liderazgo.

- Intereses comunes y apoyo mutuo.

- Logro de determinados objetivos: satisfacción de necesidades, resolución de problemas, desempeño de funciones sociales en un ámbito determinado.

Cuando hablamos de lo específico de una comunidad nosreferimosa: - Lo propio del espacio geográfico: delimitado y delimitable, con un clima, vegetación, etcétera, que le son caractenísticos. 
- La estructura so ciocultural: densidad y características de la población, edad, sexo, nivel de escolaridad, vínculos consanguíneos...

- El arraigo a la tierra, el orgullo porvivir ahí.

- La conservación de los propios ritos y tradiciones, reconocimiento y aceptación de sus símbolos, etcétera.

- La forma en que se expresan las relaciones interpersonales, los estilos concretos de participación y modos de ejercer el liderazgo.

- Los intereses que motivan a las personas y las dinámicas de apoyo mutuo, lo que se ha alcanzado y en qué nivel, a cuántos ha beneficiado, cómo se ha logrado y cuáles son los problemas porresolver.

El ámbito teritorial comunitario comprende dos ambientest: el natural y el modificado. El primero se refiere a la flora, fauna, elementos naturales, accidentes geográficos, aspectos meteorológicos... El segundo, a las modificaciones materiales, viviendas, cameteras, campos agńcolas, etcétera, que el ser humano hace, utilizando parte del ambiente natural. Los factores físicos - favorables o desfavorables- constituyen el escenario donde el hombre realiza una serie de transformaciones, según sus posibilidades técnicas y su conocimiento científico, para satisfacer las necesidades individuales, grupales o comunitanias. La planificación del medio físico como factor de desarrollo, debe llevarse a cabo en completa coordinación con los aspectos socioeconómicos; éstos han de programarse y planificarse en el marco de las posibilidades del elemento físico.

En las comunidades nurales, la concentración poblacional es más escasa que en las urbanas. Son localidades con menos de 2500 habitantes. Su desamollo depende de la capacidad y posibilidades de los seres humanos para aprovechar los recursos naturales. Las más primitivas viven sólo a expensas de tales recursos. Existen comunidades cerradaso autosuficientesy comunidades abiertas Porlo general, las primeras se identifican con las primitivas: satisfacen íntegramente las exigencias del grupo y del individuo - aunque sea de manera precania - y sus relaciones con el mundo exteriorson mínimas. Las 
abiertas pertenecen a un complejo regional de comunidades y su desarrollo - en aspectos económicos y socioculturales- depende de la región. Se trata de grupos de familias que disponen de un sistema integrado de instituciones y que adoptan ciertas conductas más o menos similares. A medida que las comunidades se van modemizando, se hacen interdependientes, sobre todo en lo sociopolítico ${ }^{5}$.

Una de las comunidades más interesantes es el municipio, pues constituye un conjunto organizado de servicios con representatividad y libertad de acción. Su estructura social no es horizontalmente plana, existe una dimensión vertical - la estratificación social- que diferencia a sus miembros en términos de supenioridad, inferioridad e igualdad. Esta valoración coloca a las personas en distintas capas o estratosy representa una de las oportunidades para ejercerel liderazgo.

\section{ANÁLISIS FENOMENOLÓGICO DE LA COMUNIDAD: UBICACIÓN, CONFIGURACIÓN, RECURSOS, FUNCIONES, RELACIONES, PROYECCIÓN Y FUTURO}

En la tiema polvorienta es un milagro que se conserven las huellas de los tenis de un joven. Continuamente hay fuertes vientos que provocan remolinos y polvaredas que nublan el horizonte. La tierra, poco fértil y caprichosa como un adolescente, sólo sirve para albergar los magueyes pulqueros que subrayan lo agreste de las agrestes rocas. Las dificultades del camino son muchas y las escasas veredas son poco transitables, pero no hay otras. Aún le falta al muchacho recorer un largo trayecto y lo más probable es que no encuentre a nadie por el camino, la comunidad más cercana está detrás del cerro que tiene ante sus ojos.

El joven viste una playera con los típicos letreros de la ropa comprada en los Estados Unidos, jeansy tenis. Lleva un paso ágil, se nota que quiere llegar, tiene urgencia por estar con los suyos; carga un itacate $^{6}$, le palpita fuertemente el corazón sólo de pensaren la cara que pondrán su madre y hermanitas al descubrir las sorpresas que les trae. Estará pocas horas, el conocido que lo pasa al otro lado le 
dijo que la vigilancia iba en aumento y no podían amiesgarse. ¡Cuántos recuerdos se agolpan en su mente!, juántas veces recomió ese camino para ir a la escuela! Valió la pena aprender a escribir, a sumar, a restar, a multiplicar... Con muchos golpes le pagó su padre, que al verle regresarle decía: No sirvesni para sacara losanimalesa pastar, parecementira quetodolo tengan quehacer lasmujeresdeesta casa ytú con sueñosdegran señor. Ya tecreesquepor saber doso tresletrasserás un catrín dela ciudad.

Un brillo aparece en sus ojos. El joven piensa que prefeńa esos tratos a tropezarse con su padre en el camino tambaleándose con los amigosy despilfarrando lo poco que tenían para comer, en unos cuantos litros de pulque. La madre del chico estaba hecha a la antigua, por eso mantuvo unida a la familia. Las de ahora ya están solas, cuidan al hijo - si lo llegan a tener- , consiguen uno que otro trabajo, aunque prefieren el de bordar, hacen verdaderas maravillas, sólo que lespagan poco, pues como no hay agua, venden el trabajo en sucio.

Luego piensa en Juanita, con ella se va a casar, pero quiere hacenlo bien, porque casi todos sus amigos han embarazado a las novias y después se han desaparecido. Recuerda entonces la muerte de Carmen, de apenas 15 años, porun aborto provocado.

Le llegaron numores de que Ruiz no resistió la tentación y cayó en el vicio de la droga. Un escalofńo lo recome y piensa: Ojalá a mí no mesuceda, estan duro estar solo allá, del otro lado, con costumbrestan distintas, siemprecon el temordela denuncia porestarindocumentado. Pero no, él le sabrá cumplira Juanita, y a su madre y a sus hemanas. Llegarán a estar muy orgullosas de él. El padre del muchacho al menos ha respetado a las hijas, ya eso resulta ganancia, porque se cuenta cada historia por ahí. Parece mentira, pero qué vergonzoso es el incesto.

Así, acompañado de esos pensamientos, llega al pequeño jacal ${ }^{7}$ del que asoma su madre. Le salen alas en los pies, se le hace tarde para darle un fuerte abrazo: ¿Cómo está usted mamá?, ccómo están mis hermanas?, tengo tanto quedecirles!, ¡sería tan bueno poder quedarme 
aquí!, peromemataría la pena denopoder conseguir trabajo. Detodas manerasregresaré, aunque porlo pronto, mañana tengo quepartir.

El joven de nuestra historia reúne todas las caractenísticas de los muchachos que habitan en la comunidad de Puerto del Ángel, ubicada en el Estado de Hidalgo, en la República Mexicana. Es una región montañosa muy aislada (está en la punta de un cerm), que ha conservado una cultura autóctona - comunidad otomí- llena de tradiciones y peculiaridades, muy vinculada a sus raíces familiares, $\mathrm{y}$ que vive con un notable atraso. Su economía agrania es de simple subsistencia, lo que provoca el éxodo rural a las ciudades.

El primer problema para visitar la comunidad, es el difícil acceso. El camino es empinado y abrupto. Se requiere de un vehículo adecuado (camioneta pick-up) y un chofercon mucha expeniencia.

En la región viven alrededor de 50 familias. Según cifras del Instituto Nacional de Geografía e Informática (INEGI) ${ }^{8}$, la población total es de 335 personas ( 173 hombres y 162 mujeres). Hay 77 menores de cinco años, 110 personas tienen entre 6 y 14 años, y 148 son de más de 15 años. Un promedio de 9.1\% de personas, está distribuido en 37 viviendas particulares - con pisos de tiema y materiales de construcción baratos- . En ninguna de las viviendas hay agua (la acarrean con ayuda de burms), ni luz (utilizan acumuladores de coches), ni drenaje (normalmente defecan al aire libre y el uso de letrinas es poco generalizado, porfalta de costumbre y porque la construcción de las mismas requiere de una tecnología especial, el suelo es muy duro). Los moradores de Puerto del Ángel no quieren irse de ahí, porque tienen su casa y un amplio temeno para moverse: los caseńos están muy distantes unos de otros.

Como el agua escasea y el maguey se da solo y en abundancia, es fácil saciarla sed con pulque. Esto fomenta el alcoholismo. En la comunidad se ingiere pulque desde muy temprana edad, porque además, la bebida tiene propiedades alimenticias. El problema es la adicción y las enfermedades que ocasiona. 
Los habitantes de Puerto del Ángel tienen ganadeńa de traspatio: aves, conejos, etcétera, y la Secretaria de Agricultura, Ganadeńa y Desarrollo Rural (SAGAR) les asesora para el cuidado de sus animales.

Pese a que la Secretańa de Salubridad y Asistencia (ssA) ha hecho labores de medicina preventiva, en verano son frecuentes los padecimientos gastrointestinales: cólera y cuadros diaraméicos más o menos severos. En invierno aparecen las enfermedades respiratorias. Hay casos de tuberculosis, desnutrición de los tres grados, hipertensión, cirrosis - por la excesiva ingestión de pulque desde edades tempranas- , etcétera. Normalmente las mujeres dan a luz en la vivienda familiary algunas mueren durante el parto. Otras, bajan del cerro al Centro de Salud para recibir atención médica.

En la comunidad, la Secretaría de Educación Pública (SEP) ya instaló un jardín de niños, escuela primaria y telesecundaria. Hay también una antena parabólica (Televisión, canal 22).

La institución gubernamental Desarmollo Integral de la Familia (DIF), a través del municipio, eventualmente ayuda a esta comunidad con desayunos escolares para la población estudiantil, cursos de capacitación a las mujeres, etcétera.

De los 335 habitantes, al menos la tercera parte habla una lengua indígena, además del castellano. 79 de los 110 niños - de entre 6 y 14 años - saben leer y escribir, y 113 de las 148 personas mayores de 15 años están alfabetizadas, pues, además de la primania, el Instituto Nacional de Educación de Adultos (INEA) ha impartido cursos de alfabetización, de primania y de secundania con el sistema abierto. Incluso, hay adultos que ya obtuvieron su certificado de secundaria.

El INEA prestó, durante un tiempo, cuatro máquinas de coser para que las mujeres de la comunidad llevaran a cabo trabajos de maquila, pero a los seis meses las recogió y las trasladó a otras comunidades.

Algunas mujeres recibieron un curso de deshilado - esta actividad gusta mucho a las nativas de la zona - pero no ha sido posible comercializar el trabajo, pues se requiere material de mayor calidad y limpio. Es difícil, por la escasez de agua. 
Pese a su aislamiento, las personas de la región reciben influencia de los modemos medios de comunicación, porque hay televisores (como hemos dicho, obtienen la energía de los acumuladores). Esto se percibe en su lenguaje y en las prendas de ropa que utilizan.

También hay divisiones y una competencia malsana por asumir el liderazgo, pero un liderazgo escondido. En realidad, muchas personas quieren los beneficios de los puestos de poder, pero no las responsabilidades.

Por la descripción que hemos hecho de Puerto del Ángel, podemos ver que se trata de una comunidad cerrada y autosuficiente, con las siguientes caracteństicas:

- ASPECTO ECONÓMICO: Escasez de capitales, bajos ingresos per cápita, métodos de producción precarios y necesidades básicas insatisfechas, agricultura deficiente (faltan medios técnicos en el cultivo y capitales para llevara cabo innovaciones en las actividades agropecuarias), industrialización incipiente.

- ASPECTO SOCIAL: Comunidad de tipo tradicional estacionaria y de gran estabilidad. Escaso desarrollo de la clase media que se refleja en el sector agnícola, por la explotación pequeña de parcelas reducidas. En el sectorindustrial hay una gran carencia de técnicos y profesionales. Encontramos altas tasas de natalidad y mortalidad; nutrición inadecuada y dietas deficientes, vivienda escasa y pobre; mal estado de salud pública y de la sanidad; bajo nivel de educación, analfabetismo; deficiente consumo de energía.

\section{ANÁLISIS VALORATIVO DE LA COMUNIDAD: FORTALEZAS Y DEBILIDADES}

En el medio rural la pobreza extrema - grave enfermedad socialse encuentra muy extendida, es profunda y severa. Se calcula que en esas áreas uno de cada dos hogares es pobre, mientras que en las zonas urbanas, lo es uno de cada nueve. La elevada dispersión de las localidades rurales y el aislamiento por la falta de medios de comunicación, complican la provisión de servicios básicosy dificultan el 
acceso a los centros educativos y laborales. Todo ello aumenta las posibilidades de perpetuar la presencia de la población excluida ${ }^{10}$.

Para evaluar la salud social ${ }^{11}$ de Puerto del Ángel utilizaremos las categońas propuestas por Pérez Adán ${ }^{12}$. Ciertas medidas investigan el defecto ${ }^{13}$, para calibrar la cantidad y calidad de desviaciones percibidas como tales porel entomo social.

Las áreas se interrelacionan y no pueden ni deben activarse aisladamente, pues los problemas de la comunidad se enfocańan de manera unilateral y sus efectos seńan intrascendentes.

Las categonías son:

$1^{\circ}$ Equidad generacional: mide la solidaridad intergeneracional a través del soporte afectivo próximo en la primera y tercera generación. Se relaciona directamente con el ámbito familiar.

$2^{\circ}$ Desigualdad (en lo esencial) ${ }^{14}$ : mide, por un lado, los grados de bienestar estandarizable y, por otro, los grados de seguridad proyectados también en el futuro a través de la esperanza de vida. Se refiere a la esperanza de vida al nacer, y a la esperanza de vida total, así como al costo social familiarpara la alimentación, vivienda, infraestructura social, educación y sanidad. Se vincula estrechamente con el ámbito social.

$3^{\circ}$ Deuda filial diacrónica: mide las acciones sociales de efectos difenidos catalogados como perjudiciales (deuda ambiental). Cuantifica y relaciona la conciencia ecológica como dato disfuncional (negativo); el consumo de energía no renovable, per cápita anual; la media de desecho de acumulación dañina, per cápita anual. También contabiliza el ahomo e inversión social familiar, que propicia la creación de patrimonio, de dote y de seguros transmisibles, si los hay. La categonáa nos da idea de la razón social y del espíritu de comunidad que prevalece. Se trata del ámbito ecológico (físico y moral). $4^{\circ}$ Conciencia cívica:

Aquí se miden tres pautas sociales. La corresponsabilidad fiscal y la prestación social, por un lado; por otro, el respeto mutuo medible por defecto en el índice de criminalidad (delitos legalmente consi- 
derados); y porultimo, la participación formal e informal en todos los ámbitos sociales. Hablamos de participación económica que se expresa en el dato disfuncional de la concentración de propiedad y de participación sociopolítica según el número de horas no remuneradas dedicadas a actividades solidarias. Es la profundidad con la que se incluye cada ciudadano en las distintas comunidades. $5^{\circ}$ Pluralidad:

Se mide por la presencia de asociaciones representativas, y por la capacidad de libre adscripción y circulación entre comunidades y sociedades intermedias, así como la permeabilidad de las barreras sociopolíticas. Se suma la movilidad social (variación de estatus de tres generaciones en la misma familia) y la diversidad. Esta última comprende tres variables: diversidad genénica (tareas domésticas realizadas porvarones), diversidad espacial (porcentaje de población nural) y diversidad de origen (población foránea). Tal categona se refiere a la inclusión — en el contexto global — de las distintas agrupaciones.

De acuerdo con estas categonas, elaboramos - para efectos de este estudio - un instrumento de análisis (cuadro 1) para detectar las presuntas carencias de salud social en cualquier comunidad. 


\section{CUADRO 1: CARENCIAS DE SALUD SOCIAL}

\section{PROBLEMAS}

\begin{tabular}{|c|c|c|c|c|}
\hline Categońas & Individuales & Familiares & Laborales & Sociales \\
\hline $\begin{array}{l}\text { Equidad } \\
\text { generacional }\end{array}$ & \begin{tabular}{|l|} 
Apatía, \\
resignación, \\
ignorancia \\
Imesponsabilidad \\
(madres solteras, \\
violaciones, \\
adulterio, incesto, \\
abandono) \\
Individualismo \\
Agresividad
\end{tabular} & \begin{tabular}{l|} 
Rechazos \\
Marginaciones \\
Desintegración \\
Inestabilidad \\
Indiferencia \\
Violencia \\
Nuevas \\
estructuras \\
familiares \\
imegulares
\end{tabular} & $\begin{array}{l}\text { Insolidaridad (no } \\
\text { se transmiten } \\
\text { oficios, o no se } \\
\text { trabaja) } \\
\text { Trabajos muy } \\
\text { absorbentes } \\
\text { Evasión o refugio } \\
\text { en el ambiente } \\
\text { laboral porque } \\
\text { ofrece más } \\
\text { bienestar }\end{array}$ & $\begin{array}{l}\text { Acaparamiento } \\
\text { o despilfamo de } \\
\text { bienes } \\
\text { Falta de } \\
\text { instituciones } \\
\text { que suplan } \\
\text { carencias } \\
\text { familiares } \\
\text { Presencia de } \\
\text { centros de } \\
\text { comupción }\end{array}$ \\
\hline $\begin{array}{l}\text { Desigualdad } \\
\text { en lo esencial }\end{array}$ & $\begin{array}{l}\text { Mala salud física y } \\
\text { psíquica } \\
\text { Desnutrición } \\
\text { Sobrealimentación } \\
\text { Falta de recursos } \\
\text { económicos por } \\
\text { despilfamo o por } \\
\text { carencias } \\
\text { Oportunismo } \\
\text { Demandas } \\
\text { desorbitadas }\end{array}$ & $\begin{array}{l}\text { Ausencia o } \\
\text { acaparamiento } \\
\text { de propiedad } \\
\text { privada } \\
\text { Falta de acceso } \\
\text { a los recursos } \\
\text { básicos } \\
\text { (alimentación, } \\
\text { vivienda, } \\
\text { educación, } \\
\text { salud...) }\end{array}$ & $\begin{array}{l}\text { Desempleo } \\
\text { Falta de } \\
\text { capacitación } \\
\text { Salario injusto } \\
\text { Trabajo } \\
\text { inadecuado } \\
\text { Fuga de cerebros }\end{array}$ & $\begin{array}{l}\text { No } \\
\text { prestaciones } \\
\text { sociales: } \\
\text { servicios } \\
\text { médicos, } \\
\text { jubilación, } \\
\text { cajas de ahomo, } \\
\text { etc. } \\
\text { Infraestructura } \\
\text { social } \\
\text { inadecuada }\end{array}$ \\
\hline $\begin{array}{l}\text { Deuda filial } \\
\text { diacrónica }\end{array}$ & $\begin{array}{l}\text { Suciedad } \\
\text { Imesponsabilidad } \\
\text { Adicciones } \\
\text { Prostitución } \\
\text { Malos ejemplos } \\
\text { Incitación al mal }\end{array}$ & $\begin{array}{l}\text { Hacinamiento } \\
\text { Promiscuidad } \\
\text { Agresividad } \\
\text { Superficialidad }\end{array}$ & $\begin{array}{l}\text { Basura } \\
\text { Humo } \\
\text { Contaminantes }\end{array}$ & $\begin{array}{l}\text { Falta de } \\
\text { conciencia } \\
\text { ambiental } \\
\text { Desperdicios } \\
\text { Contaminación: } \\
\text { tierra, agua } \\
\text { y aire. } \\
\text { Uso irracional } \\
\text { de los recursos } \\
\text { naturales } \\
\text { Pomografía }\end{array}$ \\
\hline $\begin{array}{l}\text { Conciencia } \\
\text { cívica }\end{array}$ & $\begin{array}{l}\text { Indiferencia } \\
\text { Pesimismo } \\
\text { Evasión de } \\
\text { impuestos } \\
\text { Criminalidad } \\
\text { Enquistamiento }\end{array}$ & $\begin{array}{l}\text { Mini y } \\
\text { latifundio } \\
\text { Todo el grupo } \\
\text { familiar } \\
\text { malviviente } \\
\text { Falta de } \\
\text { participación } \\
\text { ciudadana }\end{array}$ & $\begin{array}{l}\text { Perezosos } \\
\text { Ladrones } \\
\text { Depredadores }\end{array}$ & $\begin{array}{l}\text { Defraudadores } \\
\text { Destrucción } \\
\text { Crimen } \\
\text { organizado }\end{array}$ \\
\hline
\end{tabular}




\begin{tabular}{l|l|l|l|l}
\hline Categonas & Individuales & Familiares & Laborales & Sociales \\
\hline $\begin{array}{l}\text { Pluralidad } \\
\text { social }\end{array}$ & $\begin{array}{l}\text { Documentación } \\
\text { imegularo } \\
\text { indocumentados } \\
\text { Exclusiones }\end{array}$ & $\begin{array}{l}\text { Transmisión } \\
\text { generacional } \\
\text { de lapobreza } \\
\text { Inequidad de } \\
\text { género }\end{array}$ & $\begin{array}{l}\text { Huelguistas } \\
\text { Revolucionanios } \\
\text { Anarquistas }\end{array}$ & $\begin{array}{l}\text { Insatisfacción } \\
\text { Discrimina- } \\
\text { ción de grupos } \\
\text { minoritarios } \\
\text { Acciones } \\
\text { esporádicas, no } \\
\text { articuladas }\end{array}$ \\
\hline
\end{tabular}

En el siguiente cuadro presentamos las fortalezas y debilidades - desde el punto de vista individual, familiar, laboral y socialque encontramos en esa comunidad. 
CUADRO 2: FORTALEZASY DEBILIDADES DE LA COMUNIDAD DE PUERTO DEL ÁNGEL

\begin{tabular}{|c|c|c|}
\hline Categonías & Fortalezas & Debilidades \\
\hline Equidad generacional & Cohesión familiar & $\begin{array}{l}\text { Apatía, resignación e } \\
\text { imesponsabilidad } \\
\text { Desmembramiento familiar } \\
\text { poremigraciones } \\
\text { Hogares monoparentales } \\
\text { Inicio temprano en la vida } \\
\text { sexual }\end{array}$ \\
\hline $\begin{array}{l}\text { Desigualdad en lo } \\
\text { esencial }\end{array}$ & $\begin{array}{l}\text { Arraigo a la tierra } \\
\text { Sentido de identidad y } \\
\text { pertenencia } \\
\text { Apoyo de instituciones } \\
\text { gubemamentalesy no } \\
\text { gubemamentales } \\
\text { Incipiente disposición al } \\
\text { cambio y apertura }\end{array}$ & $\begin{array}{l}\text { Mala salud física } \\
\text { Oportunismo ( manipular } \\
\text { con las carencias) } \\
\text { Escasez de recursos } \\
\text { económicos por despilfamo y } \\
\text { carencias } \\
\text { Ausencia de actividades } \\
\text { productivas } \\
\text { Deficiente capacitación para } \\
\text { el trabajo } \\
\text { Falta de prestaciones sociales, } \\
\text { servicios médicos, cajas de } \\
\text { ahomo, etc. } \\
\text { Infraestructura social } \\
\text { inadecuada (sin drenaje, agua } \\
\text { entubaday energía eléctrica) } \\
\text { Condiciones temitoriales } \\
\text { adversas }\end{array}$ \\
\hline Deuda filial diacrónica & $\begin{array}{l}\text { Admiración porla } \\
\text { naturaleza } \\
\text { Amor porla tierra natal } \\
\text { Conservación de } \\
\text { costumbres } \\
\text { y tradiciones }\end{array}$ & $\begin{array}{l}\text { Suciedad } \\
\text { Alcoholismo (pulque) } \\
\text { Hacinamiento y promiscui- } \\
\text { dad } \\
\text { Contaminantes } \\
\text { Tierra semiárida }\end{array}$ \\
\hline Conciencia cívica & $\begin{array}{l}\text { Sentido de pertenencia a } \\
\text { la comunidad }\end{array}$ & $\begin{array}{l}\text { Falta de participación } \\
\text { ciudadana } \\
\text { Ejercicio inadecuado del } \\
\text { liderazgo }\end{array}$ \\
\hline Pluralidad social & & $\begin{array}{l}\text { Transmisión generacional de } \\
\text { la pobreza } \\
\text { Feminización de la pobreza } \\
\text { Precania estratificación social } \\
\text { Inequidad de género } \\
\text { Acciones esporádicasy } \\
\text { desarticuladas }\end{array}$ \\
\hline
\end{tabular}




\section{PROPUESTA DE UN MODELO DE DESARROLLO PARA SOLIDIFICAR LAS FORTALEZAS Y MINIMIZAR LAS DEBILIDADES}

En todas las formas de intervención social, el método de trabajo integra y fusiona las siguientes fases o momentos de una estrategia programada ${ }^{15}$ :

a) Estudio-investigación del aspecto de la realidad sobre el que se quiere actuar (obstáculos-necesidades, recursos-potencialidades, etcétera); ayuda a configurar un diagnóstico ${ }^{16}$. Es el momento analítico en el que preguntamos ¿quépasa?

b) Planeación y programación de las actividades que cambien la situación.

c) Realización de las distintas actividades (conscientes y deliberadas, con una intencionalidad que mantenga, mejore o transforme el aspecto de la realidad social sobre la que se actúa). Es el momento del hacer. Supone un conjunto de acciones que se dan dentro de un sistema social en un juego incierto de intercambios.

d) Evaluación de lo realizado o de lo que se está realizando, para corregir los contenidos y formas de actuación.

El último aspecto es importante porserla base de un nuevo diagnóstico. Se han de evaluar las realizaciones materiales y los cambios de actitud ${ }^{17}$. Las primeras son el resultado de los objetivos tangibles del desamollo comunal y comesponden a programas de contenidos fundamentalmente económicos: creación de nuevas fuentes de ingreso, mejora de los medios y sistemas de producción, introducción de innovaciones tecnológicas, formación de cooperativas, etcétera. Realizaciones mateniales son también las obras que contribuyen ala mejora del medio en donde se desarrollan las distintas actividades: programas que comprenden servicios básicos, comunales y de vivienda. Los objetivos intangibles ${ }^{18}$ son el cambio de actitudes, el aumento de la participación colectiva, la formación de dinigentes, el logro de una personalidad comunal independiente y, con ello, el fortalecimiento del sentido comunitario. 
Para conseguirtodo tipo de objetivos, en la actividad comunal se han de aplicarprogramas de acción con metas perceptibles, si no, el cambio de actitudes y la participación social tendrán un contenido abstracto, de poco o ningún sentido práctico. El trabajo es el medio esencial para favorecer el desarrollo, siempre y cuando esté onientado hacia fines colectivos.

Nuestro modelo busca una promoción cuya meta sea el logro del bienestar social ${ }^{19} \mathrm{y}$ la mejora en la calidad de vida ${ }^{20}$, siempre con respeto a la identidad comunal.

Pordesarrollo comunitario entendemos:

El proceso que suma los esfuerzos de los pobladores de una región, de los gnupos intermedios - escuelas, empresas, clubs, etcétera- y del gobierno, para mejorar las condiciones económicas, sociales y culturales de las comunidades, mediante el diagnóstico, plan, ejecución y evaluación de programasy proyectos para tal fin.

En todo esto - pero especialmente en el cambio de actitudesla educación juega un importante papel, porque despierta en el ser humano la capacidad para resolverproblemas, el anhelo de progresarmediante el esfuerzo propio, y de trabajar en la formación de la personalidad - individual y colectiva - sobre bases democráticas ${ }^{21}$.

En el cuadro 3 se relacionan las categonáas de salud social, con las acciones propuestas para llevara cabo un proceso de desarmollo en Puerto del Ángel. Tales acciones se agrupan en tres:

La fase inicial, que ha de fortalecer un aspecto comunitario genérico en esa comunidad, por ejemplo, mejorar la capacidad de interacción. La meta, que también debe tratar de lo genérico y universal, adecuado a toda comunidad, independientemente de su configuración social y cultural, y de su grado de desarrollo y que, en todos los casos, es una mejora en la calidad de vida para el logro de la salud social. En cambio, los aspectosque conforman el proceso son específicos, privativos de esa comunidad, aunque pueden trasladarse 0 adaptarse a otras. La parte inicial es lo que se tiene, la meta es a lo que se quiere llegary los otros aspectos del proceso son los cómos. 
CUADRO 3: PROPUESTA DE DESARROLLO PARA PUERTO DEL ÁNGEL

\begin{tabular}{|c|c|c|c|}
\hline \multirow[t]{2}{*}{ CATEGORÍAS } & \multicolumn{3}{|c|}{ PROPUESTAS } \\
\hline & Inicio del proceso ${ }^{22}$ & Aspectos del proceso & Meta del proceso \\
\hline $\begin{array}{l}\text { Equidad } \\
\text { generacional } \\
\text { (familia) }\end{array}$ & $\begin{array}{l}\text { Fortalecermás el } \\
\text { sentido de } \\
\text { pertenencia al } \\
\text { núcleo familiar }\end{array}$ & $\begin{array}{l}\text { Amory solidaridad en } \\
\text { la familia } \\
\text { Mejorar la dinámica } \\
\text { familiar } \\
\text { Promover la existencia } \\
\text { de matrimonios } \\
\text { estables }\end{array}$ & $\begin{array}{l}\text { Protección y afecto } \\
\text { para todos los } \\
\text { integrantes de la } \\
\text { familia, incluyendo } \\
\text { la primera y tercera } \\
\text { generación }\end{array}$ \\
\hline $\begin{array}{l}\text { Desigualdad en } \\
\text { lo esencial } \\
\text { (sociedad) }\end{array}$ & $\begin{array}{l}\text { Incorporara más } \\
\text { población en el } \\
\text { sistema de salud } \\
\text { Ampliar los recursos } \\
\text { alimenticios } \\
\text { Impulsar y dar los } \\
\text { medios para el } \\
\text { mejoramiento de la } \\
\text { vivienda e } \\
\text { infraestructura social } \\
\text { Acceso ala educación } \\
\text { Impulsar actividades } \\
\text { productivas }\end{array}$ & $\begin{array}{l}\text { Sistema de salud } \\
\text { Medicina preventiva } \\
\text { (vacunación, } \\
\text { nutrición, salud } \\
\text { reproductiva) } \\
\text { Acciones específicas } \\
\text { según necesidades } \\
\text { locales: capacitación } \\
\text { laboral, proyectos de } \\
\text { autoconstrucción de } \\
\text { vivienda, créditos } \\
\text { blandos... } \\
\text { Alfabetización y } \\
\text { escuelas paraniñosy } \\
\text { adultos } \\
\text { Federalismo }\end{array}$ & $\begin{array}{l}\text { Población con } \\
\text { desigualdad sólo } \\
\text { funcional, con } \\
\text { esperanza de viday } \\
\text { seguridad de } \\
\text { recursospara } \\
\text { afrontarlas } \\
\text { necesidades en el } \\
\text { futuro }\end{array}$ \\
\hline $\begin{array}{l}\text { Deuda filial } \\
\text { diacrónica } \\
\text { (ambiente) }\end{array}$ & $\begin{array}{l}\text { Crear conciencia y } \\
\text { resp on sabilidad } \\
\text { ecológica }\end{array}$ & $\begin{array}{l}\text { Campañas de } \\
\text { mejoramiento } \\
\text { ambiental: tratamiento } \\
\text { de la basura, } \\
\text { instalación y uso de } \\
\text { letrinas, elaboración de } \\
\text { composta, huertos } \\
\text { familiares, etcétera. } \\
\text { Aprovechartecnología } \\
\text { Liderazgo compartido }\end{array}$ & $\begin{array}{l}\text { Ambiente físico y } \\
\text { moral sano, en el } \\
\text { presente y el futuro } \\
\text { Contar con un } \\
\text { ahorro familiar }\end{array}$ \\
\hline $\begin{array}{l}\text { Conciencia } \\
\text { cívica } \\
\text { (inclusión } \\
\text { personal) }\end{array}$ & $\begin{array}{l}\text { Formación } \\
\text { ciudadana. } \\
\text { Promoción de } \\
\text { acciones que } \\
\text { favorezcan la civilidad }\end{array}$ & $\begin{array}{l}\text { Colaboraren } \\
\text { actividades voluntanias } \\
\text { Control de la } \\
\text { criminalidad }\end{array}$ & $\begin{array}{l}\text { Participación } \\
\text { ciudadana de } \\
\text { acuerdo con las } \\
\text { capacidadese } \\
\text { intereses personales }\end{array}$ \\
\hline $\begin{array}{l}\text { Pluralidad } \\
\text { social } \\
\text { (inclusión } \\
\text { social) }\end{array}$ & $\begin{array}{l}\text { Formación de grupos } \\
\text { representativos }\end{array}$ & $\begin{array}{l}\text { Asociacionismo } \\
\text { Participación y } \\
\text { diálogo. Formación de } \\
\text { dirigentes sociales. } \\
\text { Presencia de gnupos } \\
\text { intemedios. }\end{array}$ & $\begin{array}{l}\text { Grupos } \\
\text { representativos que } \\
\text { promuevan la salud } \\
\text { social e incluyan a } \\
\text { todos los miembros } \\
\text { de una comunidad }\end{array}$ \\
\hline
\end{tabular}


Una de las principales fortalezas de Puerto del Ángel es la equidad generacional, poreso, consideramos que el núcleo familiares el punto de apoyo para iniciar un proceso cuya meta sea la mejora en la calidad de vida, que se hará evidente en la protección y afecto para todos los miembros del grupo. En la mayonía de las personas de la comunidad existe un araigado sentido de pertenencia familiar que conviene fortalecer, mediante un proceso que mejore las relaciones interpersonales y desencadene matrimonios estables donde exista amory solidaridad.

Para combatir la desigual dad esencial, fruto de injusticias, las acciones del rubro inicio del proceso (presencia de recursos sanitarios, alimenticios, educativos, etcétera) no se encuentran enraizadas en la comunidad con la misma fuerza que en el caso de la equidad generacional. Hay que propiciarlas. Porello, los aspectos del proceso han de incorporara la comunidad al Sistema Nacional de Salud, además se han de poner en práctica acciones específicas - capacitación laboral, escuelas para niños y adultos, etcétera- según las necesidades locales y con un enfoque federalista. La meta será una población con desigualdad sólo funcional, con esperanza de vida y seguridad de recursos para afrontar las necesidades en el futuro.

En esta categońa de calidad de vida, la sociedad política, en unión con los particulares, tiene mucho qué hacerpues ha de diseñar estrategias para ${ }^{23}$ :

- Asegurar la nutrición adecuada y servicios de salud especialmente a grupos vulnerables (madres, niños, ancianos, etcétera).

- Apoyar las actividades de los agricultores y brindarles tecnología.

- Capacitarpara el trabajo.

- Propiciar oportunidades de empleo productivo ${ }^{24}$.

- Revalorar las tareas femeninas.

- Fomentarla asistencia escolary las aspiraciones educativas.

- Impulsar programas que complementen el ingreso de las familias máspobres.

- Promover una vivienda digna, con espacios y servicios adecuados, 
calidad en su construcción y seguridad juńdica en su tenencia.

- Mejorar la infraestructura social, etcétera.

Para impulsarel autodesamollo regional de México, una solución a largo plazo, aunque prionitaria, es respetar la autonomía de los estados y municipios ${ }^{25}$ y fortalecer el federalismo que combate la asfixiante centralización. Porello se recomienda ${ }^{26}$ :

- Modernizar las estructuras administrativas locales.

- Estimular la consolidación de ciudades intermedias y pequeñas como destinos altemos, para evitar las migraciones a los grandes centros urbanos.

- Reforzar la integración de ciudades pequeñas con sus áreas nurales de influencia.

- Favorecer la articulación de ciudades productivas locales y regionales que privilegien la generación de empleo y posibiliten mayor integración y participación de los agentes y sectores económicos.

- Propiciar, mediante instalaciones públicas, el crecimiento de centros nurales de población que ofrezcan una alternativa atrayente para reagnupara las poblaciones más dispersas y hacer viable la provisión de servicios básicos.

Las pequeñas regiones se caracterizan por la simbiosis con el ambiente geográfico, las personas están más cerca de la naturaleza y el habitattiene espacios para conservar la flora y la fauna. Sin embargo, debido en ocasiones a la comupción, la apatía y la pobreza extrema, es posible que exista un uso imacional de recursos naturales - físicosy humanos- expresados en destrucción, agresividad, etcétera.

Porello, el inicio del proceso en la categońa deudafilial diacrónica es crear conciencia y responsabilidad ecológica, para lograrun ambiente físico y moralmente sano que perdure ${ }^{27}$. Esto se garantiza si se dispone de un ahorro familiar. Proponemos campañas de mejoramiento ambiental: clasificación de desechos, instalación y uso adecuado de letrinas, etcétera. Lo importante es superar las acciones 
ecológicas esporádicas e inconexas, y promoveraquellas que beneficien a todos, en el presente y el futuro. También se ha de potenciar el cooperativismo, las campañas informativas y las actividades culturales; favorecer la formación y cohesión de grupos, el liderazgo compartido, la raigambre de las personas con su medio, la afirmación de la identidad cultural, la autosuficiencia - que implica el ahorroen los principales ámbitos de la vida, la motivación y el estímulo ${ }^{28}$.

El inicio del proceso de la categońa conciencia cívica se refiere a aquellas acciones que forman tal conciencia, de manera que la meta sea la espontánea participación ciudadana, de acuerdo con las capacidades e intereses personales. Los aspectos del proceso se encuentran estrechamente vinculados con actividades de voluntariado, gratuitas y sin ningún interés de lucro o de estatus. Junto con ello ha de haber una sustancial disminución de la criminalidad. La fortaleza que hace viable la participación ciudadana es el sentido de pertenencia, que ayudará a superar la pasividad y el ejercicio inadecuado del liderazgo. Lo importante es transformardesde abajo la sociedad política y desamollar nuevos estilos de vida, mediante la mayorparticipación de la sociedad civil. Para ello se ha de evitar toda forma de autoritarismo, patemalismo y manipulación.

Finalmente, la categonía pluralidad social demanda que todos los sectores participen, de acuerdo con sus posibilidades, en la mejora de la calidad de vida. Portanto, se requieren tres niveles de ciudadanos activos: voluntarios, técnicos y expertos. El inicio del proceso ha de ser laformación de gnupos representativos que, a través del asociacionismo ${ }^{29}$, la participación y el diálogo canalicen actitudes de inconfomidad, discriminación o resentimiento, para evitar actos violentos o cualquier tipo de desorden social. Se ha de daratención prioritaria a los grupos másvulnerables: mujeresy niños, jóvenes, pueblosindígenas ${ }^{30} \mathrm{y}$ jomaleros agnícolas, personas con discapacidad o de la tercera edad...

Ahora bien, ccómo lograr una sinergia que eche a andartodo el proceso?, cómo darcontinuidad a los proyectos pese a los vaivenes políticos, al relevo generacional y a las ideologías de moda?Lo más 
importante es que cualquier tipo de labor parta de una caracteństica comunitania genérica, asumida como convicción, y encamada de manera vital sobre todo en los líderes, quienes mantendrán presente la esperanza y conservarán el entusiasmo, a pesar de las adversidades. Vale la pena llevar a cabo acciones conjuntas entre el gobiemo y la sociedad, proyectosy programas específicos de desamollo comunal.

El proceso es largo, el retraso es ancestral y crónico, y quizá transcurran varias generaciones para lograr cambios que incidan en el desarmollo regional y nacional. Precisamente por eso hay que trabajar, ya desde ahora, buscando mejores resultados que los obtenidos a la fecha. Lo importante es promover la participación activa y solidaria de todos ${ }^{31}$, junto con la intervención de instituciones gubernamentales, no gubemamentales y voluntarias, para suministrar ayudas y llevara cabo acciones que aumenten la eficacia y capitalicen el esfuerzo y el trabajo de los integrantes de la comunidad.

Una comunidad tan rezagada como Puerto del Ángel necesita cuando menos al principio - un fuerte apoyo institucional. Sin embargo, sin la participación de los destinatarios, este apoyo puede perpetuarse, favorecer el oportunismo y el acostumbramiento y, paradójicamente, fomentar el desinterés por salir del rezago. Ahora bien, si la ayuda no se despolitiza y se articula, es muy probable que dé resultados tan pobres como los actuales (la comunidad no tiene agua entubada, luz ni drenaje). Por ello, es necesario combatirla comupción en todoslossectoresyniveles.

Es indispensable un trabajo con grupos que estén unidos por objetivos comunes ${ }^{32}$. Cada grupo ha de ser una unidad de acción con tareas concretas, pero abierto a la labor comunal e interdisciplinaria. Así será posible vertebrar todos los grupos con la ayuda de los líderes sociales, y producir un movimiento coordinado y total. Por ello, el asociacionismo ${ }^{33}$ y las actividades voluntarias son tan importantes en este tipo de acciones. Un supuesto indiscutible es el respeto al pluralismo ideológico, religioso y moral. Tratándose de regiones apar- 
tadas, la utilización de los medios audiovisuales y de comunicación a distancia resultan muy útiles.

\section{CONCLUSIONES}

Todas las propuestas anteriores las confima la experiencia del estudio de campo en variadas comunidades nurales. Tal expeniencia nos permite ratificarque la sociedad enferma gravemente cuando se vinculan condiciones deficitarias de alimentación, salud, educación y vivienda, con ingresos insuficientes e inestables. Ello se traduce en una falta de oportunidades para desarrollar las capacidades productivas, sociales y culturales de las personas ${ }^{34}$. Hacen falta estrategias diferenciadas y más profundas para que los beneficios de la política social ${ }^{35}$ de alcance general, extiendan su efecto igualitario en la población con mayores rezagos.

Pensamos que los grandes lastres de nuestro país son la ignorancia, la apatía, el oportunismo y la comupción. Esto genera un profundo retraso en el desarrollo. Por ejemplo, debido a la ignorancia hay una serie de pensamientos mágicos, totalmente infundados, que se han convertido en verdades inamovibles (en algunas regiones de México está muy mal visto que una mujer corte el pelo a los hombres, incluso niños).

Se requiere una verdadera cruzada, y una participación ciudadana consciente y responsable, para integrar a todos los miembros del tejido social en el proceso de cambio. Los promotores - expertosy voluntanios- han de despertarla conciencia adormecida de las personas, sostener los esfuerzos a lo largo del proceso y evitar el desaliento $^{36}$. Todo ello, sin hacerse indispensables.

Vale la pena subrayar algunos puntos básicos para que este proceso dé buenos resultados. Hay que partirdel hecho de que los miembros de una comunidad pueden y deben desarrollar su capacidad para resolver sus propios problemas, y de que nunca tendrá la misma fuerza el cambio impuesto que el proveniente de la iniciativa de los destinatarios y protagonistas de este cambio. Los problemas se 
han de abordarde modo holístico, incorporando democráticamente a todos. Pero, para adoptarla democracia, es necesario que las personas tengan un mínimo de preparación y que no rechacen, al menos al principio, la aplicación de un programa, la ayuda extema.

Algunas estrategias muy concretas son:

- Junto con el aspecto comunitario genénico, que será el inicio y base de todo el proceso de desarrollo, habrá que encontrar el problema eje, pues éste entorpece cualquier posible avance. Por ejemplo, no se puede desarrollar ninguna actividad productiva si falta el drenaje.

- Aprovechar símbolos, tradiciones, folkore, efeménides, etcétera, y evitar la emulación indiscriminada de patrones extranjeros y de índices económicos que otros han logrado.

- Impulsarla promoción comunitaria desde la escuela. El maestro es un líder natural.

- Asegurarel uso amplio y eficiente de los recursos humanosy mateniales de que dispone el país y cada región.

- Promoveruna capacitación nural integral que responda a las necesidades regionales de adiestramiento técnico-agropecuario, administrativo y financiero; $y$ que aproveche la expenencia de instituciones privadas y públicas, universidades, centros de educación superiore infraestructura técnica agropecuaria.

- Registraracciones y sus resultados, para promoverlas experiencias de éxito y no recomenzarcontinuamente.

- Contar con una adecuada organización y equipo multidisciplinario. Evitar duplicidad de esfuerzos.

- Cumplirlas promesas.

- Proporcionarsiempre un contenido educativo a cualquiertipo de asesonía y de ayuda matenial. 


\section{REFERENCIAS BIBLIOGRÁFICAS}

${ }^{1}$ Ponencia presentada en el 12 congreso anual «Citizenship and Exclusión» de la Society for theAdvancementof Socio-Economics(SASE)., London School of Economics., Londres., 7 al 10 de julio., 2000.

${ }^{2}$ ANDER-EGG, Ezequiel., «Metodología y práctica del desarmollo comunitario» Vol. 1., ¿Quéesel desarrollo dela comunidad?., Editorial LumenHvmanitas., Argentina., 1998., p.33 y 34

${ }^{3}$ En casos excepcionales es posible prescindir del aspecto teritorial, por ejemplo, el pueblo judío.

${ }^{4}$ Cfr. ESCALANTE F. Rosendo et.al., Investigación, Organización y Desarrollo dela Comunidad., Editorial Oasis., México., 1990., p.53y 54.

${ }^{5}$ Cfr. ESCALANTE. F., Rosendo et.al., Op.cit., p.33 a 35.

${ }^{6}$ Pequeño bulto de comida, de ropa o de enserespersonales.

${ }^{7}$ Casita muy pobre y con materiales de construcción baratísimos.

${ }^{8}$ Cfr. Resultadosdefinitivosdel Conteo dePoblación y Vivienda., Hidalgo., Tomo II., 1995.

${ }^{9}$ Los criterios de evaluación son de ESCALANTE F. et.al., Op.cit, p.73 y 74.

${ }^{10}$ Cfr. Programa para superarla pobreza (1995-2000)., Secretańa de Desamollo Social (SEDESOL)., México., 1998., p.32.

${ }^{11}$ Gradación de los estados de felicidad colectiva o excelencia grupal en ámbitos sociales - familia, asociaciones, comunidad, etcétera — donde más fácilmente se pueden optimizary minimizar los conflictos.

${ }^{12}$ Cfr. La salud social., Editorial Trotta., Madrid., 1999., p.17, 118 y ss. Las categonías se refieren tanto a realizaciones materiales como a cambios de actitud.

${ }^{13}$ Deben revisarse las conductas disfunciones y desincentivarse, incluso con acciones coercitivas.

${ }^{14}$ Incluimos el matiz de la desigualdad en lo esencial, porque la desigualdad funcional es legítima.

${ }^{15}$ Cfr. ANDER-EGG, Ezequiel., Reflexionesen torno a losmétodos del trabajo social., Editonial El Ateneo S.A. de C.V., México., 1992., p.83 y 84.

${ }^{16}$ Para el diagnóstico hay que considerar todos los factores y sujetos de la 
realidad comunitaria.

${ }^{17}$ Cfr. ESCALANTE et.al., Op.cit., p.262 a 264.

${ }^{18}$ Son intangibles pero hasta cierto punto cuantificables, por ejemplo, registrando el número de participantes en una reunión de padres de familia o de colaboradores en una campaña ecológica.

${ }^{19}$ Conjunto de programas, prestacionesy servicios que proveen satisfactores básicos para el bienestarhumano y el mejoramiento social. Va más allá del mero desamollo económico.

${ }^{20}$ La calidad de vida requiere, además de un estándareconómico para satisfacer las necesidades básicas, la presencia de condiciones y posibilidades reales para el crecimiento y desamollo humano de todos.

${ }^{21} \mathrm{Sin}$ lo educativo, la democracia se convierte en manipulación de los ignorantes.

${ }^{22}$ Todos en la comunidad deben sentirque han descubierto el aspecto genénico que será el punto de partida, valorarlo, defendenlo y saber que eso los une, pues les da pertenencia e identidad.

${ }^{23}$ Cfr. ESTADOS UNIDOS MEXICANOS, PRESIDENCIA DE LA REPÚBLCA, Decreto por el queseaprueba el Plan Nacional deDesarrollo 1995-2000 [31 de mayo de 1995].

${ }^{24} \mathrm{El}$ apoyo a la pequeña y mediana industria evita el totalitarismo estatal o la presencia de transnacionales que tal vez busquen sólo el beneficio económico. La pequeña y mediana industria serán rentables si reciben asesonía científica y tecnológica. Por ello, es tan importante la estrecha vinculación entre los sectores productivo y educativo.

${ }^{25}$ En los aspectos administrativos y de salud hay mucho más autonomía que en lo educativo.

${ }^{26}$ Cfr. Plan Nacional deDesarrollo 1995-2000.

${ }^{27}$ Comesponde a las autoridades desplegaruna política ambiental adecuada para detener el deterioro ecológico, estimularla inversión en infraestructura y la actualización y difusión de tecnologías limpias, así como velarpor el cumplimiento de las normas de protección ambiental. (Cfr. Plan Nacional deDesarrollo 1995-2000) .

${ }^{28}$ QUINTANA CABANAS, José Ma., Losámbitos profesionales dela ani- 
mación., Narcea S.A. de Ediciones, Madrid 1993., p.9.

${ }^{29}$ Asociaciones - con estructura, continuidad, fines conscientes y concretos- que encaucen la tendencia natural de las personas a reunirse. Si es posible, obtener un reconocimiento juńdico.

${ }^{30}$ La promoción del desamollo de los pueblos indígenas ha de respetar la niqueza cultural de su historia, su lenguay sus tradiciones. Hay que promoverla participación de los pueblos indígenas en la planeación, definición, ejecución y administración de programas destinados a mejorar la salud, el bienestar social y la educación de sus propias comunidades. (Plan Nacional deDesarrollo).

${ }^{31}$ En la promoción social han de evitarse dosposturas emóneas: pensarque las comunidades son realidades homogéneas con intereses compartidos; $\mathrm{y}$ que todas las personas quieren mejorarsu comunidad y ponen los medios para ello. (Cfr. ANDER-EGG, E., Metodología y práctica del desarrollo dela comunidad., Vol. 1, p.99).

${ }^{32}$ Cfr. KISNERMAN, Natalio., La comunidad., Editorial Hvmanitas., Buenos Aires., 1984., p.75.

${ }^{33}$ Fenómeno de madurez social que se apoya en la tendencia natural de las personas a reunirse, pero que necesita estructuras estables - si es posible con reconocimiento juńdico- y orientadas a finalidades conscientes y concretas. (Cfr. QUINTANA CABANAS. J., Op.cit., p.82).

${ }^{34}$ Cfr. Programa para superar la pobreza (1995-2000)., SEDESOL, p.14y 15.

${ }^{35}$ Política social: conjunto de acciones - relacionadas con la forma de actuación del Estado- , cuyo propósito es mejorar la calidad de vida con la prestación de servicios, para satisfacer necesidades básicas de los ciudadanos, y asegurar unos mínimos de renta, una buena alimentación, salud, educación y vivienda. Esta política - a través de leyes concretas- debe disminuir las desigualdades sociales injustas y atender a personas que, por razones de edad o impedimentos físicos o psíquicos, no pueden generar recursos pormedio de su trabajo.

${ }^{36}$ Se deteniora la confianza cuando los proyectos se están recomenzando siempre o por el incumplimiento de las promesas. 


\section{BIBLIOGRAFÍA}

ANDER-EGG, Ezequiel., Metodología y práctica del desarrollo comunitario. Vol. 1. ¿Quéesel desarrollo dela comunidad?, Editonial Lumen-Hvmanitas., Argentina., 1998.

Reflexionesen torno a losmétodos del trabajo social., Editorial El Ateneo S.A. de C.V., México., 1992.

ESCALANTE FORTÓN, Rosendo. MINANO, Max., Investiga ción, Organización y Desarrollo dela Comunidad., Editorial Oasis., México., 1990. ESTADOS UNIDOS MEXICANOS, PRESIDENCIA DE LA REPÚBLCA, Decreto por el queseaprueba el Plan Nacional deDesarrollo 1995-2000. 31 de mayo de 1995.

KISNERMAN, Natalio., La comunidad., Editorial Hvmanitas., Buenos Aires., 1984.

PÉREZ Adán, José., La salud social., Editorial Trotta., Madrid., 1999.

QUINTANASCABANAS, José Ma., Losámbitos profesionales dela animación., Narcea S.A. de Ediciones., Madrid., 1993. 